\title{
The Property Right Analysis And The Contract Governing About The Group Events Of Flight-delay
}

\author{
XueLin Wang \\ Department of Studies \\ Civil Aviation Flight University of China \\ Guang Han,Si Chuan,China \\ scuwxl@sina.com
}

\begin{abstract}
The group events of flight-delay reports out the fact that when the time property rights can not be bounded completely, the passengers and airways always "look for a rent" in community field. In my opinion, to control the group events of flight-delay we should remove the community field or control the rent value and cost for rent. Comply with a long range, give more time property right of flight-delay to passenger is good to promote efficiency of deploying resources.
\end{abstract}

Keywords- Flight-delay; Group Events; Property Right Analysis; Contract Governing

The group events of flight-delay, caused by flight-delay, are some fierce language, body, and even legal conflicts between passenger groups and enterprises of air transport. A survey of Sichuan Shuangliu Airport shows that since August 2003 to August 2004 year, more than 40 group events were caused by flight-delay, and showed a gradual upward trend [1]. Since it had a very negative impact on civil aviation normal operation and the image of the civil aviation industry, the group events of flight-delay has become the focus of air defense security control. Security could control for group events, reduce conflict loss based on crisis management. But the better way to reduce conflicts and improve resource utilization efficiency is contract governing.

\section{A CIVIL AVIATION CONTRACT IN THE COMMUNITY FIELD , RENTS AND RENT-SEEKING}

Objectively, the group events of flight-delay are a step by step conflict between some passages and staffs during the waiting time. Domination by the laws of the group events, the conflicts are easily escalate and difficult to control. There are some researches strive to find the answer in industry standards and system perfection. For instance, improving the quality of passenger service to avoid and reduce the conflict as much as possible, making the coordination system of some organizations (mainly means to airlines, airports and airport services) more perfect to aviation service, establish the rapid emergency dealing system [2] and so on. To some extent, these methods can alleviate and even avoid conflicts. But in substance, these methods only make the afterwards emergency dealing with the group events of flight-delay develop into controlling and dealing when it happens, not able to touch essence of the event, why it happens. Under the hypothesis of rational man, the truly difference between group events and individual events is the consistency of group interests. When flight-delay happens, passengers' common interests are the "loss" caused by the delay, so the focus of dispute between passengers and aviation service organizations also is the compensation for the "loss".

We think that in addition to the form and amount of the compensation, the most crucial is to determine the rationality of the compensation that is why the airlines should be responsible for flight-delay. Passengers request only based on the tickets they have bought. In substance tickets are a contract signed between passengers and airlines, which define rights and obligations. Passengers request for default compensation because the airline can't provide service products (flight-delay) according to the contract (ticket), and airlines expect to off duty by majeure. Obviously, when the contract seriously provide all kinds of circumstances on airline flight-delay, and stipulate the responsibility of the events of delay clearly, the group events of flight-delay will no longer occur. Unfortunately, the contract theory tells us that complete contract is difficult to achieve [3]. So, the substance of the group events of flight-delay is contract parties, that is group of travelers and airlines' interest demands on contract (ticket) matters not covered, which called seeking rent in community field of contract.

The property economists consider that, in a transaction, because costs to obtain complete information and detailed description of the contract transaction are too high, so that there is always some rights in the external of contract. Both the two parties of the contract have the possibility to get benefit, and this part of the right which does not respect is in the community field. The full value in community field is called "rent", the contract parties spend resources to capture the value of the community field is the "rent-seeking", and the resources they spend is the cost of their rent-seeking. Only "When people believe that the benefits this behavior bring out exceed the cost, they will use the right, on the contrary, when they consider that the benefit is insufficient to cover the costs, they would not use the right, so that this property will place in the community field" [4].When the value of these community field is large enough (the cost of rent-seeking is low enough), people will start "rent-seeking" to get the benefit. When one party's rent-seeking behavior encroach the others' right, or the two parties request the same rental value, the conflict generate. 


\section{The Rental VAlue Growth of Flight-Delay EVENT AND THE COST REDUCTION OF RENT-SEEKING}

The rental value in community field and rent-seeking costs are likely to change. "The value may seem small at the signing of the contract, but value increased prior to the expiration of the contract which contracting parties did not make provisions in the contract, it is possible to dispute" [5] . Due to the constraints of rent value and rent-seeking cost previously, air travelers and airlines do not care the value in community field. The rent-seeking conflicts do not exist. As the time value highlights and the absolute value of time delay increases caused by flight delays, air travelers and airlines begin to pay attention to the community field of flight delays property, and participate in rent-seeking actively. The two conflict parties in group events of flight-delay enter the contract to rent-seeking in community field may be caused by two reasons. The first is the rental value growth of flightdelay; the second is the decline in the cost of rent-seeking.

\section{A. The Rental Value Growth of Flight-delay}

With the development of economy, the value of flight punctuality rate for passengers and airlines is on the rise.

The rise of passenger's time value increases their benefit. The evaluation of the time value of passengers on the one hand depends on the height of the flight punctuality requirements. From a certain perspective, the high speed, accuracy and safety are typical characteristics superior to other modes of transport aviation [6], for which passengers pay a higher purchase cost (price). Therefore, passengers have high demands on the flight punctuality necessarily. By contrast, travelers will feel more pain waiting for the same time. Another key factor impacts assessment of the time value is the size of passenger revenue per unit time. Passengers at the same time preference in the case, because of their income levels rise, the opportunity cost per unit time is increasing - the evaluation of the time value of travelers is positively related to per capita income [7]. Although passenger's revenue per unit time is different, the evaluation of their time rises when the economy grows. We set the time preference of travelers a, set average revenue per unit time $X_{p}$, set the time value $V_{p}$, there are functions:

$$
V_{p}=a f\left(X_{p}\right), \text { and } \frac{d V_{p}}{d X_{p}}>0
$$

View from the airline, the increasing cost of flight punctuality rate improves the airline rent-seeking revenue. In addition to force majeure conditions, in order to ensure a higher flight punctuality rate, the airlines need to spend more resources in the unit configuration, route planning, coordinating other aspects of the airport. Obviously, the higher requirement of punctuality rate, the higher the cost. Moreover, with the increase of punctuality rate, the cost will inevitably accelerated increase-- The resources of punctuality rate increased from $99 \%$ to $100 \%$ will be definitely enough for punctuality rate increased from $59 \%$ to $60 \%$.If a certain time error allowed, the smaller the error, the higher the cost spent by airline. On the contrary, the higher the requirements of flight punctuality of passengers, the greater the value of delay time for airlines. If set allowable error rate $b$, flight punctuality rate $X_{a}$, the delay value $V_{a}$, there are functions:

$$
V_{A}=(1-b) g\left(X_{A}\right) \text {, and } \frac{d V_{A}}{d X_{A}}>0, \frac{d^{2} V_{A}}{d X_{A}{ }^{2}}>0
$$

\section{B. The Decline in the Cost of Rent-seeking}

The rent-seeking cost of flight-delays decreases. The enhancement of the value of "flight delay" is not sufficient to allow passengers and airlines actively rent-- If the rentseeking costs are too high, they may still be willing to let the time value in the community field. But that is not the case, at least in the view of passengers; they are able to actively claim their rights than before. This on the one hand, stems from the integrity of the system of laws and regulations, passengers have convenient and economical channels fighting for their interests; On the other hand, due to the cost of passenger groups composition decreases, network communication is convenient carrier to achieve this. In this case, passengers can share the rent-seeking cost to reduce the cost of each individual, which greatly enhance the possibility of rent-seeking of travelers. Set the legal aid costs $C_{l}$, passengers organizational costs $C_{0}$, passengers rent-seeking total $\operatorname{cost} \mathrm{C}_{\mathrm{p}}$, there are:

$$
C_{p}=y\left(C_{L}, C_{O}\right) \text {, and } \frac{d C_{P}}{d C_{L}}>0, \frac{d C_{p}}{d C_{O}}>0 .
$$

It seems the airline to maintain its "flight delays" rent low-cost advantage, although slightly weakened, still very strong. Organization and information advantages are the two factors to guarantee the low-cost of airlines rent-seeking. Airlines' organizational advantage is its advantage in its existing organizations compared with passengers in the process of seeking legal aid. Therefore, when travelers' organizational advantage increases $\left(\mathrm{C}_{\mathrm{o}}\right.$ reduction), the airline's will reduce, and rent-seeking costs rise. So the airline's organizational strengths changes inversely with the cost of passengers' organization. Airline's information advantage is the benefits in explaining the reasons for flight delays due to information asymmetry. Information advantage varies inversely with the airline's rent-seeking cost. Set rent cost airlines $C_{a}$, information advantage $C_{m}$, then the function:

$$
C_{A}=h\left(C_{M}, C_{O}\right) \text {, and } \frac{d C_{A}}{d C_{M}}<0, \frac{d C_{A}}{d C_{O}}<0 .
$$

The conflict between passengers and airlines rent in the community field should meet the following conditions:

$$
\left\{\begin{array}{l}
V_{\mathrm{P}}=\operatorname{af}\left(\mathrm{X}_{\mathrm{p}}\right) \geqslant C_{p}=y\left(C_{L}, C_{O}\right) \\
V_{A}=\operatorname{ag}\left(X_{A}\right) \geqslant C_{A}=h\left(C_{M}, C_{O}\right)
\end{array}\right.
$$

The two inequalities are independent. The simultaneous establishment of them is the necessary and sufficient conditions of the appearance of flight delays' group events. Moreover, the difference around the inequality is greater, the contractual benefits are greater too, thus the rent-seeking 
motivation is higher and the conflict is more probable to happen.

\section{THE CONTRACT GOVERNING OF GROUP EVENTS OF FLIGHT-DELAY}

First to note is that rent-seeking behavior may make a reasonable use of the value in the community field and increase whole benefit. Barzel takes use of the change of the North Sea oil development rights to descript this issue [8]. Therefore, from a normative perspective, we do not want negative for group events dubbed nature. However, this article focuses on how to avoid conflicts caused mass incidents, and the contract management is the fundamental method to solve the problem. From the following two aspects be helpful in resolving this issue.

\section{A. Elimination of Flight Delays in the Community Field}

Through directly define flight delays ownership property you can simply remove the community field. That is, given airline or passenger to the full ownership of the time value of flight delays. When airlines are given full ownership, passengers can only endure flight delays harm; when travelers are given full ownership, the airlines will be responsible for all the passengers of flight delays corresponding compensation.

Some people may worry over the rights violations of both contract parties, that airlines may have the endless flight delays because of full property rights, for travelers over propose flight delay compensation requirements because of full property rights. The former can be achieved through the hand of the market equilibrium__ “travelers' vote with their feet", and choose other means of transportation alternatives to air travel; the latter can be eliminated the delay time through fair compensation price_for example, you can choose to use average passenger hours income as compensation standards. In addition to the problems, the market will automatically give a satisfactory solution: Airline ticket prices will automatically seek a new equilibrium, passengers will automatically trip or not, how to make their own choices on the trip.

After elimination of the public sphere, once the flight delays incident happen, passengers and airlines are clearly aware of their rights and interests, and does not product conflict because of seeking compensation. Flight delays group events will lose inherent roots.

\section{B. Under the Premise of Flight Delays in the Community} Field, Reducing Both the Contract rent-Seeking Space

We must avoid the Inequality af $\left(X_{p}\right) \geq y\left(C_{L}, C_{0}\right)$ and $\operatorname{ag}\left(X_{A}\right) \geq h\left(C_{M}, C_{0}\right) \quad$ simultaneously established, or to minimize the difference between the left and right values of inequality. Thus, lowering the left value or increasing the right value in the inequality is viable option. Different factors has different nature, a simple analysis is as follows:

Reduce traveler time preference a. This is not a mere contractual issue, passenger groups, passengers' time preference will change with lifestyle. On the whole, there is always time preference growing trend. However, from a shorter time perspective, passengers are willing to wait a long time because of a lower ticket prices, or by lowering ticket prices or providing equivalent services to reduce traveler time preference.

Traveler time value $X_{P}$ inevitably increases with income growth. Flight punctuality rate can be controlled to some extent by the airlines. Since $\mathrm{X}_{\mathrm{A}}$ and $\mathrm{V}_{\mathrm{A}}$ are a positive correlation, and $\frac{\mathrm{d}^{2} V_{A}}{d X_{A}{ }^{2}}>0$, therefore, the airline can be maintained $\mathrm{X}_{\mathrm{A}}$ at a certain level so that guarantee $\mathrm{V}_{\mathrm{A}}$ not be too high. From this perspective, allowing a certain airline flight delays, which can greatly reduce the value of rentseeking in the community field. Even if travelers have rentseeking behaviors, airlines are willing to compensate through a certain way, but the premise of all is the compensation must be $\mathrm{M} \leq C_{A}-V_{A}$.

From a long-term process of social and economic development perspective, the cost of travelers of legal aid CL and the cost of organizational groups $\mathrm{CO}$ tended to decrease. Thus, the cost of travelers rent-seeking CP also showed a long-term downward trend. But on the specific incident, through appropriate disposal means, which can improve the organizational costs of travelers. For example, given comfort and disposal to highly time-sensitive targeted passenger, consciously contribute visitors to dispersion.

Airline information superiority $\mathrm{CM}$ may be effectively controlled. However, this control should be from airline outside. For example, through the intervention of a third party can greatly reduce airlines the advantages of flight delay information: require airlines offering the proof of flight delays causes, and the evidence of unavoidable conditions need to get the permit of non-airline interest groups, such as the weather should be proved by the local meteorological department, for security reasons you should be proved by the public security department. In the case of assuming an independent third party, airline information superiority inevitably reduced, thus enhancing airlines rent cost. At the same time, the long-term decreased trend of passenger organizations cost $\mathrm{CO}$ must be lead to airlines rent cost increased.

\section{SUMMARY}

In order to reduce the group conflict of flight-delays, the Civil Aviation Administration published a "the guidance financial compensation for flight delays" (hereinafter referred to as "guidance"), require airlines to formulate their own specific economic compensation. However, the effect of "guidance" is unsatisfactory. From the perspective of contract governing we found that although it is nominally defined in a series of right relationships caused by flightdelay, but due to information constraints [9], and the lack of definition of property rights of third part surveillance mechanism [10], the property rights of flight delay time is difficult to delimit, the community field still exists. On the contrary, "guidance" make the flight delays passengers who unclear the time value of property requires clarity, enhance passenger expectations of a, increases the rent-seeking space 
for passengers and airlines. It is entirely possible for the flight delays have a negative impact on group events.

Overall, due to the rising of delay time value and the falling of rent-seeking, passengers must start rent-seeking in a long-term; but in a specific delays incident, the parties concerned through active response and effective disposal, could reduce rent-seeking travelers enthusiasm, thereby reducing group events of flight-delay, or the degree of conflict. In contrast, the rent-seeking value and cost of airlines is easier to control --through the control of their information advantage can be more substantial increase in the cost of rent-seeking, and then properly controlled flight punctuality rate can reduce or even eliminate the airlines rent-seeking space. In this meaning, while retaining the community field, giving passengers more flight delay time value of property could enhance the resource allocation efficiency.

\section{REFERENCES}

[1] He Yuanhua. Wei zhongxu. Xu Lingjie. Shuangliu Airport acts of unlawful interference investigation and analysis [J]. China Civil Aviation Flight University of China.2006, (1). 7-10

[2] Xu Zhiguo. Properly handle contradictions and avoid flight delays disputes [J]. Chinese civil aviation .2007, (8) 79.

[3] Lars Werin,Hans wijkander,Contract Economics [M]. Economic Science Press ,2003,14-15

[4] Barzel. Property Rights Economic Analysis [M]. Shanghai: Shanghai Joint Publishing Shanghai People's Publishing House, 1997.89.

[5] Barzel. Property Rights Economic Analysis [M]. Shanghai: Shanghai Joint Publishing Shanghai People's Publishing House, 1997.93.

[6] Masaki Ota Aviation Transport Economics [M]. Beijing: Aviation Industry Press ,1988,2-4

[7] Masaki Ota Aviation Transport Economics [M]. Beijing: Aviation Industry Press ,1988,174

[8] Barzel. Property Rights Economic Analysis [M]. Shanghai: Shanghai Joint Publishin,1997.98-99

[9] Shixin Liang. Flight delays dispute analysis and recommendations [J]. Civil Aviation Management, 2004, (9)

[10] Pan Yonggang .Face of flight delays calling public trust mechanism [J]. Civil Aviation Management, 2004, (10) ,27-29 